\title{
Getúlio e a seca: políticas emergenciais na era Vargas
}

Frederico de Castro Neves

Universidade Federal do Ceará

RESUMO

Este artigo procura analisar as relações entre o Estado e os retirantes das secas de 1932 e 1942, durante o período de Getúlio Vargas como presidente. As intervenções realizadas para estabelecer um controle episódico sobre essa população migrante, que invadia e saqueava cidades e armazéns, podem abrir janelas de compreensão bastante amplas para examinar os mecanismos de constituição do poder de Vargas e a permanência do "trabalhismo" no Brasil, assim como as relações entre os modelos liberal e paternalista de política.

Palavras-chave: seca; migrantes; controle social.
ABSTRACT

This article aims the analysis of the relationship between State and the "retirantes" of the 1932 and 1942 dry seasons, during the government of the President Getúlio Vargas. The State actions tried to control this migrating population, which invades and plunders cities and food stores. This analysis can open such a useful window to see the mechanisms that constitute Vargas power and the "trabalhismo" in Brazil, as well as the relations between paternalistic and liberal models of politics.

Keywords: drought; migrants; social control. 
De modo geral, as análises sobre a "era Vargas" enfatizam, por um lado, os aspectos de repressão e de manipulação do movimento operário e, por outro, as características "paternalistas" de construção de um mito de "pai dos pobres" através de concessões e benefícios. No entanto, uma série significativa de trabalhos vem se direcionando para a conclusão de que a "era Vargas" se constitui num momento em que tais elementos - violência e manipulação, concessões e benefícios - se combinaram na construção de uma imagem do "trabalhismo" como expressão idônea de uma nação pacificada, unificada e corporativa. Buscando esclarecer as formas de instituição de um padrão de relacionamento entre Estado e sociedade no Brasil, em que os métodos estabelecidos pelo modelo "paternalista" se combinam com aqueles oriundos do modelo "liberal", especialmente no que diz respeito ao campo das relações econômicas, estes trabalhos podem igualmente explicitar as especificidades da formação da classe trabalhadora no Brasil. Ao mesmo tempo, podem-se esclarecer as relações entre as pressões e as contrapressões que as forças sociais empreendem no conjunto das lutas sociais, estabelecendo um movimento contraditório que desafia as teorias do "controle social".

Desta forma, a partir dessa perspectiva, pode-se concluir que o getulismo mantinha com as "leis" de mercado uma relação ambígua, buscando alcançar um pleno equilíbrio entre autoritarismo político e liberalismo econômico. Os momentos de crise, neste caso, são especialmente favoráveis para uma análise destas formas de relacionamento, constituindo-se em janelas privilegiadas para esclarecer parte deste período tão estudado da história brasileira.

Getúlio Vargas, durante o período de 1930 a 1945, enfrentou duas grandes secas: 1932 e 1942. Nesses dois momentos distintos, as ações emergenciais diferiram em modo e intensidade, conforme as circunstâncias do contexto histórico nacional e internacional e de acordo com o pacto estabelecido com as oligarquias locais.

\section{ESTADO E MERCADO}

Em 1932, pela primeira vez a intervenção do Estado brasileiro em período de seca no semi-árido cearense ocorreu de forma coordenada e centralizada. Desde 1877, quando a seca assumiu o caráter moderno que ainda hoje possui, as propostas de resolução ou de simples amenização da "questão climatérica" que assolava os Estados do "Norte" não passavam de respostas localizadas às invasões de retirantes famintos que assolavam as cidades, reivindicando trabalho e comida. Mais do que uma irregularidade pluviométrica, a seca pôde ser percebida, a partir de então, como um fenômeno social inserido nas redes de relacionamentos políticos e socioeconômicos, em que as condições de pobreza de uma parce- 
la significativa da população que habita o semi-árido são gravemente acentuadas em momentos de crise. No entanto, tratada sempre como um fenômeno da natureza, a seca fortalece suas raízes na sociedade brasileira e reforça uma teia política e social que se opõe aos parâmetros estabelecidos da modernidade.

De qualquer maneira, de 1877 a 1932 estava gestando-se uma nova estrutura de sentimentos em relação à pobreza generalizada a que a seca dava visibilidade. Um novo relacionamento entre retirantes, governantes e habitantes das cidades se tornava o centro de uma série de atitudes com relação aos miseráveis em momentos de escassez, quando uma legitimidade social era atribuída às ações coletivas que as multidões de retirantes já começavam a empreender'.

Assim, um amplo programa de criação de campos de concentração, em que os retirantes fossem induzidos a entrar e proibidos de sair, foi implementado com total apoio da Interventoria Federal no Ceará. A fim de prevenir a "afluência tumultuária" de retirantes famintos a Fortaleza, cinco campos localizavam-se nas proximidades das principais vias de acesso à capital, atraindo os agricultores que perdiam suas colheitas e se viam à mercê da caridade pública ou privada. Dois campos menores situavam-se em locais estratégicos de Fortaleza, conectados às estações de trem que traziam os famintos, impedindo que eles circulassem livremente pelos espaços da capital. Uma vez dentro do campo, o retirante era obrigado não só a permanecer nele durante todo o período considerado de seca, mas deveria submeter-se a condições de moradia, relacionamento, trabalho e comportamento regulados pelas normas irredutíveis ditadas pelos dirigentes indicados pelo interventor - prefeitos nomeados e engenheiros do IFOCS. Os campos, portanto, pretendiam impedir a mobilidade física e política dos retirantes através da concessão de rações diárias e de assistência médica. O controle dessa imensa população - o maior campo, na cidade do Crato, chegou a abrigar quase 60 mil pessoas - representou um gigantesco esforço de organização, que tinha seu contraponto nas ações violentas das multidões de retirantes que ameaçavam tomar em suas mãos a resolução de suas aflições ${ }^{2}$.

Por outro lado, o contexto político, econômico e institucional em que se desenrolou a seca de 1932 foi, em vários aspectos, diferente das secas anteriores.

Em primeiro lugar, as mudanças institucionais decorrentes do movimento que chegou ao poder em outubro de 1930 se efetivaram de maneira desigual nos Estados que compunham a Federação. Pode-se afirmar que "a 'Revolução de 30' no Ceará, tal como ocorreu em outros Estados do Brasil, desalojou do poder as oligarquias mais tradicionais, sendo o espaço político temporariamente ocupado pelos tenentes revolucionários e pelas oligarquias dissidentes que assimilaram o ideário político da aliança liberal”’.

A fragilidade da estrutura partidária e a crise econômica que se arrastaram 
desde meados do século XIX favoreceram a centralização do poder nas mãos dos interventores e permitiram a ampliação da ação revolucionária, apesar da "heterogeneidade de intuitos das suas mais fortes correntes formadoras"4.

Para o "Norte", visto de uma forma geral e superficial, o engajamento no processo revolucionário significava a possibilidade de uma "redenção política e econômica", em função da presença marcante, na direção nacional do movimento, de importantes lideranças locais, como Juarez Távora, que poderiam trazer para a região benefícios que eram negados, segundo os reclamos das elites, pelos governantes “oligárquicos” da República Velha. Como se pode observar, tratavase de uma continuidade política com relação ao paternalismo oligárquico em suas formas mais elementares - a troca de favores, o beneficiamento pessoal - que se procurava restaurar num momento de ruptura da ordem institucional. O que se pretendia com uma "participação mais efetiva na política do País" era a proximidade de grupos locais específicos com as esferas reconhecidas do poder federal, situadas em São Paulo e Rio de Janeiro.

Assim, as possibilidades de uma ação centralizadora das Interventorias se faziam mais fortes no Ceará que nos Estados do sul do País. Apesar disso, não seria possível aos interventores desenvolver uma ação de governo, mesmo que prioritariamente apenas para "implementar as medidas administrativas do Go110 verno Federal”, sem que houvesse um intercâmbio político com as elites dirigentes e, de modo mais amplo, com as classes dominantes locais.

Em segundo lugar, a crise nacional provocada pela Revolução Constitucionalista de São Paulo colocava em questão a necessidade de uma resolução imediata do "problema" da seca.

De um lado, a centralização política nos primeiros momentos do período revolucionário favorecia a tomada de decisões sem a consulta aos grupos locais nem o respeito a trâmites democráticos de participação política. Podiam ser tomadas medidas de assistência à população "flagelada" a partir de ordens diretamente emanadas do Ministério da Viação e Obras, via Interventoria, sem necessariamente passar pela intrincada rede de interesses patrimoniais envolvidos nas relações de poder nos sertões. Segundo um membro da "comissão technica constituida para inspeccionar os actuaes trabalhos da Inspetoria das Sêcas", sr. Maurício Joppert, essa foi uma das mais fortes razões para o sucesso do "programma desenvolvido pelo Sr. Ministro José Américo", realizado em um profícuo "ambiente technico e moral elevado" e dentro do "mesmo methodo de trabalho, a mesma uniformidade de commando" 5 .

De outro lado, o comprometimento das lideranças cearenses com o movimento de 30 impunha a necessidade de um posicionamento imediato contra as pretensões paulistas. Pretendiam esses líderes que o alinhamento total com a "Re- 
volução" garantiria para o "Norte" uma posição favorável no jogo de forças políticas a nível nacional, já que a vitória governista ameaçaria, mesmo que superficialmente, o predomínio paulista sobre a política e a economia nacionais, considerado pelas elites locais como o principal fator da sua decadência. $\mathrm{O}$ jornal $\mathrm{O}$ Povo (em 24 de agosto de 1932), portanto, imediatamente, aprovou a criação do "segundo Batalhão provisório destinado a colaborar militarmente com as forças federais, em defesa da Ditadura, ou seja, da própria Revolução de 30, ora agredida pelos reacionários paulistas". A “inoportuna Rebelião Paulista”, segundo ainda o jornal, "traz, em seu bojo, uma sede de domínio que, se tivesse de ser saciada, acarretaria a desgraça do Norte", já que "a hegemonia paulista sempre foi funesta aos nossos interesses regionais". A "Revolução de 30", ao contrário, veio "criar para o Norte condições próprias até então desconhecidas". Como, então, hesitar em sua defesa?

Assim, a atenção dada pelo governo à rebelião paulista se justificava aos olhos da imprensa e das lideranças cearenses, apesar da necessidade de uma ação imediata em razão da seca.

Em outubro, porém, com o fim das hostilidades em São Paulo, a atenção do governo pôde ser cobrada com maior intensidade.

Com a rebellião paulista a attenção de nosso povo voltou-se para o sul. Enquanto se fallava no front, no movimento de tropas e na organização de batalhões provisórios, enquanto se exaltava o desassombro das forças dictatoriais e a estratégia do general Klinger, os nossos pobres do Campo de Concentração eram de algum modo esquecidos. Hoje, porem, quando a Pátria Brasileira foi integralisada no regime da ordem e da paz, chamamos a attenção de nossos leitores, novamente, para o Estado do Campo de Concentração do Ipú, o qual acabamos de visitar nesta semana ${ }^{6}$.

As queixas apareciam timidamente na imprensa. Os relatórios as desprezavam. A assistência aos retirantes da seca cearense ocupou um evidente segundo plano nas prioridades governamentais daquele momento, o que, em função das razões já mencionadas, não causou o desagrado que se esperaria entre jornalistas e políticos locais. Do ponto de vista material, contudo, a ajuda financeira concedida pelo Ministério da Viação ao governo do Ceará, destinada à assistência aos retirantes, passou da média de 200:000\$000 de abril até agosto de 1932 para 800:000\$000 em novembro, chegando a 1.500:000\$ em março de 1933. ${ }^{7}$ O fim da guerra civil abria os cofres da Nação e as cobranças podiam ganhar maior visibilidade no espaço público.

Diante dessas limitações e possibilidades, o governo pôde realizar seu "amplo" programa de assistência aos retirantes, intervindo diretamente no mercado local. Essa intervenção não se deu somente no âmbito do mercado de trabalho, 
através da criação de vagas "artificiais" de trabalho em obras públicas destinadas a "ocupar" uma mão-de-obra desmobilizada num momento de crise, mas também, de forma incisiva, no mercado de alimentos, regulando os preços e o abastecimento de produtos de primeira necessidade.

O "commissariado de alimentação publica”, reorganizado em abril, já estabelecia uma intervenção maciça nos preços e nas quantidades de produtos disponíveis no mercado, especialmente de Fortaleza. Tais medidas foram ampliadas pelo Decreto n ${ }^{\circ}$ 796, de 17 de outubro de 1932, criando a "Commissão de Abastecimento Publico", "que ficou incumbida da fiscalização de todo territorio do Estado". Vale a pena transcrever na íntegra as "principais funcções da commissão de abastecimento":

a) organizar na capital do Estado o cadastro de todos os armazéns, mercearias e quaesquer estabelecimentos em que sejam expostos á venda generos de primeira necessidade; b) proceder ao levantamento do stock de artigos de primeira necessidade existentes naquelles estabelecimentos comerciaes; c) manter perfeito serviço de estatística dos generos alimenticios entrados na capital do Estado, por qualquer via; d) organizar semanalmente e fazer publicar todos os sabbados tabellas de preços maximos para a venda de generos alimenticios; e) obter cotações de differentes artigos no interior, na capital e nas demais praças do paiz; f) solicitar das repartições publicas informações sobre os preços de transportes de mercadorias; e g) finalmente, exercer rigorosa fiscalização relativamente á execução das tabellas de preços em vigor.

Com a nova comissão, segundo avaliação do interventor, "todo commerciante ficou impossibilitado de reter generos alimenticios em seus estabelecimentos ou depositos, com o intuito de provocar elevação de preços". A penalidade aos infratores chegava a multas de $500 \$ 000$ a 1:000\$000 “e ao dobro, nas reincidências". A ação contra os especuladores, objetivando controlar os preços dos alimentos consumidos especialmente pelos retirantes, abrangia todo o território do Estado e atingia "commerciantes grossistas", "retalhistas" e "encarregados de fornecimento nos serviços da Inspectoria Federal de Obras Contra as Secas", evitando que "os operarios e a população do Estado fossem explorados na compra dos generos de primeira necessidade".

O Governo Provisório usava toda a sua autoridade, advinda da situação discricionária daquele momento, para intervir nas relações de mercado e regulamentar as atividades que pudessem alterar a ordem pública, gerando a insatisfação popular pelo aumento dos preços. O mercado, nessa visão autoritária, tinha uma função na segurança pública; regular suas atividades, portanto, era atribuição do Estado, tal como o entendiam os principais mentores do novo regime. A visão liberal de igualdade de todos diante do mercado era progressivamente substituí- 
da pela noção de que "o Estado Nacional erguia-se em função do fundamento da desigualdade dos homens e das nações e postulava soluções políticas específicas para cada povo" e que se tratava, portanto, fundamentalmente, de "buscar os meios de tornar a autoridade mais justa e mais eficiente no enfrentamento da questão social da necessidade". O Estado, assim, em contraposição à visão liberal, "não mais devia restringir-se às suas funções protetoras de polícia, mas atuar como um verdadeiro coordenador na distribuição da riqueza nacional". Isso se combinava perfeitamente com o "ideal de justiça social" preconizado pelos "revolucionários", cujo "critério de valor" era exatamente "o ideal de respeito ao trabalho e aos frutos do trabalho"".

A "questão social" que se formulava então relacionava-se, dessa maneira, à idéia de "necessidade", cujas exigências se ajustavam, em parte, às reivindicações da multidão que se apossou das mercadorias em Orós e outras cidades do Ceará nas primeiras semanas de 1932, anunciando uma forma de ação - o saque e a invasão das cidades - e um sujeito coletivo - a multidão - que se generalizariam a partir da década de 1950, instituindo uma tradição legitimada socialmente. Por vias diversas, o autoritarismo do regime do pós-30 e o comunitarismo "tradicional" dos retirantes em busca de alimentos percebiam o mercado muito mais pela lente da "moralidade" - daquilo que deve servir ao Estado ou aos pobres em momentos de escassez profunda - do que pela percepção liberal de um automatismo advindo de leis invisíveis que não se pode ou não se deve deter ou regular.

Por outro lado, a "distribuição da riqueza nacional" também estava atrelada às especificidades de cada momento, de cada situação. A escassez proporcionava ao regime uma rica oportunidade para exercitar essa capacidade de controlar o mercado e de impor uma ampla regulamentação no sentido de garantir "o ideal de respeito ao trabalho e aos frutos do trabalho". As críticas ao liberalismo, que reifica o mercado, encontraram nesse momento de crise uma forte justificativa e uma ampla base social no sentido de garantir um apoio geral às intervenções estatais nas relações econômicas. O regime, assim, tornava público um domínio considerado como pertencente à esfera privada.

Até 1930, as relações entre os governantes e os retirantes haviam se baseado num terreno movediço mal delimitado, de um lado, pelos costumes tradicionais da vida sertaneja e, de outro, pelo "liberalismo oligárquico" que dominava a esfera do Estado no Brasil, com todas as suas peculiaridades. As demandas apresentadas pelos refugiados da seca, nesse contexto, eram recebidas pelas autoridades ora com desdém - confiantes na capacidade do mercado de reequilibrar-se por si mesmo e na secular submissão do homem do campo -, ora com temor diante das possibilidades de revolta contidas na formação da multidão como agente de organização popular. No segundo caso, porém, as intervenções no merca- 
do de trabalho e alimentos se tornavam comuns, regulando a ordem econômica para que a miséria e a fome não se alastrassem a níveis insuportáveis, destruindo as redes de relações sociais e políticas que mantinham - ou pretendiam manter o homem preso aos vínculos da dependência pessoal, da obediência e da submissão. Do ponto de vista dessas autoridades, foi daí - deste alastramento da fome e do risco da mortalidade em massa - que surgiu a reação destruidora dos retirantes, como um "espasmo" de preservação última da vida.

Os governantes do regime autoritário do pós-30 não pensavam diferente. Entre eles também predominava a "visão espasmódica", que condenava as ações da multidão de retirantes ao campo dos "instintos", ${ }^{10}$ mas, ao contrário do que acontecia antes, não hesitavam no momento de intervir na ordem econômica, pois o desequilíbrio social significava, para eles, ameaça à ordem política, ao regime, à segurança nacional.

Essa intervenção, todavia, por mais que pareça fruto de um planejamento centralizado e racional, portanto moderno, se conectava às expectativas construídas dentro do "modelo" paternalista de ordenamento das relações sociais. Curiosamente, mas nem tanto, as perspectivas racionalizadoras do regime "revolucionário" de 30 articulavam-se aos padrões ditos "oligárquicos", mais uma vez, dando a esse momento a característica de complexidade pela qual é conhecido e estudado.

Nos momentos em que o liberalismo predomina nas esferas de estruturação do Estado, direcionando as políticas sociais, o conflito com os padrões paternalistas se estabelece com maior intensidade; nestes momentos, a resistência "moral" na percepção do mercado em tempos de crise se fortalece e ganha visibilidade em ações diretas e, muitas vezes, violentas.

\section{GuERRA E SECA}

As formas de relacionamento entre retirantes e autoridades, estabelecidas pelo regime do pós-30 permaneceram, pelo menos em alguns aspectos, na seca de 1942. A possibilidade de envolvimento do Brasil na Segunda Grande Guerra, no entanto, se apresentava como um elemento a fornecer características peculiares a esse momento. Era, mais uma vez, um elemento que agia de modo a favorecer uma intervenção direta no mercado de trabalho e alimentos, conforme ocorreu em 1932. O clima de guerra favorecia soluções autoritárias.

Os técnicos encarregados de observar e analisar as condições climáticas e as obras públicas encaminhadas em função das secas já previam que o ano de 42 poderia ser difícil.

O inverno de 1942 encontrou, entretanto, o proletariado rural do Nordeste enfra- 
quecido para qualquer resistência maior; sem recursos do ano anterior, em que as chuvas foram notoriamente escassas; lutando, desde o início, contra a carestia exorbitante dos generos alimentícios de primeira necessidade; sem o apoio indispensável do proprietário rural que, com raras exceções, o abandonou à sua sorte, ou melhor, o entregou a proteção dos poderes públicos aos primeiros sinais de mau inverno. Daí a inquietação provocada pelas primeiras irregularidades das precipitações e que culminou no quasi pânico que se seguiu à falta de chuvas no equinócio de Março ${ }^{11}$.

O superintendente identifica, aqui, mais uma vez, a passagem de uma proteção realizada no âmbito da propriedade privada para a proteção "oficial" a cargo do Estado. Por outro lado, a "inquietação" da população rural se verificava em função não só de um "mau inverno" de 1941, mas principalmente de uma "carestia exorbitante" que a atormentava já no início de 1942, chegando a um "quasi pânico" em março, quando o "mau inverno" foi seguido por outro. O adjetivo "exorbitante", utilizado pelo técnico do governo, pode significar, enunciado nesse momento do Estado Novo, uma impaciência com relação às forças do mercado de alimentos, que, ao primeiro sinal de seca, se "desequilibra", permitindo um aumento desordenado de preços. Isso pode demonstrar o Estado de ânimo dos intelectuais e técnicos - encarregados de interpretar e solucionar os problemas sociais gerados pela "seca" - para com o liberalismo, nesse momento em que um processo de centralização política já se efetivara com relativo sucesso no Brasil, na vitória da política trabalhista e corporativista de Getúlio Vargas. Assim, a necessidade de uma rápida e eficiente intervenção governamental no mercado de alimentos e trabalho ganhava espaço, mais uma vez, entre as autoridades encarregadas de promover a "proteção dos poderes públicos" ao "proletariado rural".

Em 19 de março de 1942, dia de São José, ${ }^{12}$ a seca foi novamente "decretada" no Ceará, com todos os atributos que já conhecemos. O jornal O Povo, de 27 de março de 1942 anunciou que "Fortaleza começa a ser invadida pelos Flagelados da Sêca", e que dificilmente se poderia conter "a avalanche humana que ruma" para as "regiões menos expostas á sêca". A "visita dos deserdados da sorte", "andrajosos e famintos", vinha provocando as igualmente conhecidas providências tomadas pelos órgãos estatais, com vistas a "atenuar o flagelo".

Alguns prefeitos procuraram sensibilizar o próprio presidente Vargas, enviando-lhe telegramas relatando a situação em seus municípios. Foi denunciada uma "calamidade indescritível", uma "horrenda situação", em que "nossos patrícios" encontravam-se "morrendo de fome". Os "infelizes famintos" percorriam as cidades em "afluência tumultuária", esgotando as reservas da caridade particular $^{13}$. 
Uma "negociação coletiva através da arruaça" 14 já estava em andamento, e os canteiros das obras públicas gerenciadas pelo DNOCS (Departamento Nacional de Obras Contra as Secas, reestruturado a partir do antigo IFOCS) transformaram-se imediatamente em arenas políticas onde se desenrolava um embate estranho de pressões e contrapressões, em que mais valia o envolvimento pessoal que domina os códigos da cultura do que uma racionalidade universal baseada na legalidade ou na capacidade técnica.

Os "chefes", engenheiros que comandam os acampamentos e o trabalho, tinham que tentar conciliar a capacidade da obra em receber novos trabalhadores, a necessidade técnica de cada uma delas e o direcionamento político dado pelos dirigentes do órgão. Eles, assim como os policiais, procuravam evitar maiores conflitos, mas reconheciam a urgência da fome e, assim, aceitavam as bases de legitimação que a própria multidão imprimia aos seus movimentos. Quando ocorria algum assalto aos acampamentos e fornecimentos, geralmente o resultado do "roubo" era "mais tarde distribuído a todos, com advertências", pela própria polícia.

A atitude com relação ao saque era ambígua: a polícia tomava, mas imediatamente devolvia os alimentos aos saqueadores. Mas essa ambigüidade era característica do modelo paternalista assumido pelo Estado, transformando-se em paternalismo oficial. Nas mãos dos chefes e dos responsáveis pelos alistamentos recaía a responsabilidade de negociar com a multidão nas áreas de trabalho, enquanto nas cidades essa era tarefa dos padres, prefeitos e outras autoridades locais. Com a "conversa", o "contato", a "promessa", os chefes procuravam "acalmar" uma multidão que se impacientava com a falta de medidas ou com a demora nas atitudes práticas de distribuição de alimentos. Precisam, obviamente, conhecer em profundidade os padrões culturais e as expectativas sociais dos retirantes, associados a uma agricultura de tipo tradicional - a pequena propriedade (própria ou arrendada) familiar - cujos objetivos econômicos se resumiam à obtenção de uma precária e provisória "segurança alimentar". Sem esse conhecimento, ele "estará perdido": a multidão, fora de controle, poderia tomar atitudes imprevisíveis ou, no mínimo, violentas, assumindo com as próprias mãos a tarefa de obter os alimentos tão necessários ${ }^{15}$.

O impacto dessas invasões sobre o comércio, sobre as autoridades locais e sobre a população urbana pode ser facilmente imaginado, apesar das dificuldades dos observadores em avaliar com exatidão suas dimensões, e dos interesses dos correspondentes dos jornais em exagerar o evento, além dos limites da "invasão". Os retirantes procuravam as áreas centrais das cidades, áreas normalmente próximas aos mercados de alimentos, feiras livres e prédios das prefeituras. As áreas residenciais não eram diretamente afetadas pela presença dos famintos, muito em- 
bora eles circulassem pedindo esmolas; mas, como em toda cidade pequena, as notícias corriam rápido e a presença de uma multidão que muitas vezes alcançava um número expressivo causava, quase sempre, curiosidade e espanto.

O próprio interventor Menezes Pimentel resolveu, em telegrama, alertar o presidente da República do perigo das concentrações de retirantes nas cidades cearenses:

\footnotetext{
"Para evidenciar agudeza situação, cumpre-me esclarecer V. Ex. que estão se concentrando milhares famintos numerosos municipios Estado, havendo cerca 6.000 Sobral, 4 a 5.000 Senador Pompeu, 1.000 Jaguaribe, aproximadamente 2.000 Canindé e outros tantos Tauá e muitos outros pontos interior. Nesta Capital existem cerca 5.000 flagelados."
}

Concluiu que "praticamente não há mais zona onde não se manifeste fome, não se concentre população flagelada pedindo trabalho"”.

No entanto, o alistamento de um número exagerado de novos trabalhadores, praticamente da noite para o dia, provocou distúrbios inesperados na estruturação dos trabalhos, alterando a rotina produtiva e exigindo modificações técnicas. O superintendente do DNOCS assinalou que "a capacidade de absorção de trabalhadores dessas obras não é proporcional ao montante das dotações correspondentes", indicando problemas financeiros. Mas, ao mesmo tempo, ressaltou que "a construção mecânica intensiva - que não pode ser alterada de repente, para a manual, sem graves prejuízos - reduz grandemente esta capacidade, e a Inspetoria terá de examinar cuidadosamente cada caso, para evitar a desorganização dos seus serviços". Assim, algumas obras, ou alguns setores no interior de alguma obra, não puderam ser modificados imediatamente de modo a permitir o "emprego de grande escala de operariado não especializado". Colocavam-se em confronto uma racionalidade técnica voltada para a alta produtividade e melhor aproveitamento dos recursos com menor custo, e uma necessidade de atender à "intensificação dos socorros". A solução - "verificada a insuficiência desses recursos" - foi "atacar novas obras, em pequeno número, e distribuídas de maneira a atender razoavelmente às necessidades das diferentes regiões evitando-se uma dispersão de esforços que a experiência de crises anteriores tem mostrado ser, por todos os motivos, desaconselhável". Além dessas obras novas, especialmente a construção de estradas, outras medidas foram sugeridas para fixar os homens que se deslocavam em determinados pontos fora das cidades, onde causavam problemas políticos, sociais e administrativos: "a distribuição de famílias de retirantes pelas vazantes das bacias hidráulicas dos açudes públicos construídos", "a localização de famílias retirantes nas áreas irrigadas dos Postos Agrícolas" e "a localização, ainda em pequenos lotes, de famílias retirantes nas áreas das 
bacias de irrigação já dominadas pelos canais e ainda não cultivadas pelos respectivos proprietários" ${ }^{\prime 17}$.

Do ponto de vista organizacional, portanto, a presença dos retirantes causava problemas administrativos que devia ser resolvidos dentro dos limites de uma implacável racionalidade técnica, que procurava alocar as "peças" disponíveis de acordo com uma lógica de melhor aproveitamento dos recursos e de menor índice de desperdício, de acordo com uma visão ampla da organização social, vista de cima, como um todo, que desprezava as injunções e "interferências" culturais e locais, especialmente se vindas do modelo paternalista das relações sociais. Os retirantes, segundo a visão dos técnicos, deveriam ser distribuídos pelo território, em obras e serviços a serem definidos exclusivamente pelo órgão técnico competente, inseridos em relações de trabalho que não dominavam, mas que eram as mais adaptadas (tecnicamente falando) às circunstâncias. Esta racionalização dos socorros evitaria a "esmola desmoralizante", o que foi reforçado pelo correspondente de O Povo (28 de março de 1942) em Alto Santo, afirmando que "gente pobre aqui não aceita esmola, pede trabalho". A demanda por trabalho, como se verifica, não especificava a natureza do objeto a ser produzido nem as relações de produção a serem empregadas. Pressupõe-se que o retirante, pelo Estado de absoluta necessidade, aceitaria qualquer trabalho, sob quaisquer 118 circunstâncias.

Mas a situação crítica parecia, por vezes, reforçar os laços de reciprocidade estabelecidos nas relações entre o Estado Novo e a sociedade. Em Canindé, por exemplo, apesar da fome e do desespero enfatizados detalhadamente em cada reportagem, "o povo espera porque o homem que o governa é o mesmo que o salvou em 1932". O jornalista, procurando resumir as esperanças de todos os que estavam envolvidos por esse manto do paternalismo oficial, concluiu: "todos esperam nas providências do Dr. Getúlio Vargas!" (O Povo, 5 de maio de 1942).

As correntes de migração e movimentação dos retirantes, como já era sabido, acompanhavam as obras estabelecidas pelo DNOCS, e os técnicos, intelectuais e políticos pareciam unânimes em afirmar que "somente os serviços públicos poderiam concorrer ponderàvelmente para minorar a situação, que se agravava progressivamente". No entanto, apesar dos créditos abertos pelo governo federal "para atender ao custeio de diversos serviços a cargo do $1^{\circ}$ Distrito da Inspetoria de Sêcas", chegou-se à conclusão de que "a crise não podia ser tão facilmente superada, como se julgava anteriormente, embora o flagelo fôsse realmente parcial" ${ }^{\prime \prime}$.

A solução, mais uma vez, foi a emigração; agora, todavia, dentro de um novo contexto, em que o "discurso do Poder reduz brasilidade a parâmetros geo- 
gráficos e econômicos" e que a grande tarefa imposta pelas novas condições da realidade nacional seria "eliminar os 'vazios demográficos' e fazer com que 'as fronteiras econômicas coincidam com as fronteiras políticas"”, conforme discurso do presidente Vargas em Manaus, em 1940, pregando uma "cruzada" para a Amazônia nos moldes da "Marcha para o Oeste" que se efetivava então no centro-sul do País ${ }^{19}$. O momento favorável permitiu a formação de um "Exército da Borracha", formado para lutar no front dos seringais amazônicos e arregimentado nas áreas secas do semi-árido nordestino, especialmente do Ceará.

As complicações econômicas decorrentes da Segunda Guerra Mundial apresentaram para os países aliados o problema do abastecimento de borracha, um elemento importante na fabricação de veículos, pneus e armamentos em geral, tornando a sua obtenção uma questão estratégica muito importante para o esforço de guerra. Assim, os seringais da Amazônia retornaram ao centro do comércio internacional da borracha devido à expansão bélica japonesa sobre as áreas de produção na Ásia. Contudo, "como o problema do povoamento do vale [amazônico] ainda não tinha sido resolvido, organizou-se em caráter emergencial uma nova onda migratória para o Norte", e, para isso, o governo criou, em novembro de 1942, o SEMTA (Serviço Especial de Mobilização de Trabalhadores para a Amazônia) com o "objetivo de alistar e recrutar trabalhadores para a 'Batalha da Borracha"'. A especial coincidência de tais efeitos e necessidades da guerra e a eclosão de mais uma seca fez com que a sede do novo órgão fosse instalada em Fortaleza, onde mais facilmente se poderiam encontrar "flagelados candidatos a seringueiros" 20 .

Antes mesmo da criação do SEMTA, a emigração para o Norte já havia se iniciado nos moldes conhecidos das outras secas, sob a coordenação do Conselho de Imigração e Colonização do Brasil em cooperação com a Delegacia Regional do Trabalho. Um esquema de transportes foi montado para receber e transladar os retirantes para Belém e Manaus. O Lloyd Brasileiro colocou um de seus navios à disposição para fazer a linha de Fortaleza a Belém "até que se desafoguem os maiores centros de aglomeração dos flagelados no Ceará". Os embarques, porém, foram suspensos após "os torpedeamentos dos nossos navios mercantes em águas da Bahia pelos bandidos fascistas" (O Povo, 20 de junho e 31 de outubro de 1942).

Ao mesmo tempo, novos campos de concentração foram organizados na capital, procurando evitar o trânsito indesejado dos retirantes pelas ruas da cidade. Em outubro, os campos foram unificados no campo do Alagadiço, sob a direção das irmãs Marianas, do Dispensário dos Pobres. Uma comissão de senhoras, liderada pela sr. ${ }^{a}$ Anita Gentil Barbosa, administrava os serviços, procurando oferecer socorro para as crianças, vestuário e assistência hospitalar, tendo conse- 
guido um "generoso auxílio do comércio" e prometendo prestar contas do dinheiro arrecadado, "uma vez findos os seus trabalhos" mado de "albergue", no entanto, não era "rigorosamente o que desejavam realizar as autoridades do Ministério do Trabalho", com dois mil retirantes se amontoando "sob a sombra de árvores frondosas, encontrando-se, por conseguinte, expostos á chuva", em condições higiênicas precárias.

A campanha realizada pelo SEMTA, entretanto, possuía contornos "científicos". A propaganda passou a ser o principal mecanismo de mobilização dos flagelados e de adesão da opinião pública, utilizando intensamente um conjunto de imagens e textos - segundo Alcir Lenharo, "um dos recursos largamente utilizados pelos intelectuais do Estado Novo" - que construíam a idéia de uma Amazônia ideal, terra da "promissão", da "fartura" e da "esperança", que se contrapunha ao Ceará, terra da "seca". A genialidade do artista francês Jean Pierre Chabloz veio somar-se a essas propostas, produzindo uma série de pinturas e cartazes em que foram veiculadas as imagens paradisíacas de uma Amazônia tropical, feliz e próspera, onde todos encontravam trabalho e onde a água era abundante. Ao mesmo tempo, os desfiles dos "soldados da borracha" pelas ruas de Fortaleza, assim como os programas radiofônicos diários, contribuíam para a formação de uma adesão em massa à emigração e, por conseguinte, um apoio da população cearense à contribuição brasileira ao esforço de guerra dos aliados. Não foi por acaso que os retirantes eram alistados e preparados como soldados que iriam se deparar com uma "batalha" e que estavam envolvidos numa "guerra”. O discurso bélico colaborava fortemente com a imposição de um conjunto de medidas drásticas aparentemente que se contrapunham radicalmente à realidade da seca. O fim da guerra iria demonstrar o contrário: o soldado foi esquecido, e o campo de batalha, abandonado.

O "albergue" do Alagadiço tornou-se um posto de seleção para os candidatos a seringueiros, onde o Serviço Especial de Saúde Pública concentrou seus esforços para inspecionar aqueles que estavam realmente aptos para enfrentar o trabalho na floresta amazônica. Um acordo entre Brasil e EUA garantia remédios, passagens, salários para médicos e enfermeiros, enfim, toda uma infra-estrutura de apoio ao serviço. Os médicos, liderados pelo dr. Albino Figueiredo, trabalhavam sem parar e chegavam a inspecionar 900 pessoas num só dia, "um verdadeiro 'record' e uma prova evidente da eficiência do Serviço Especial de Saúde Pública”, segundo O Povo de 5 de janeiro de 1943.

Também, como resultado desse acordo, foi instalado em Fortaleza o escritório central da Divisão de Migração, sob a direção do dr. Charles Wagley, professor de Sociologia da Universidade de Columbia (NY), e um "homem culto e de extraordinária capacidade de trabalho". Segundo afirmou O Povo em 13 de 
janeiro de 1943, “o ilustre sociólogo americano vem tendo uma atuação eficiente no desempenho da importante missão que lhe foi confiada pelo governo daquela nação amiga". Era ele, então, quem supervisionava todo o trabalho de recolhimento, seleção, assistência médica e embarque dos retirantes que se dirigiam à Amazônia. A necessidade de controle sobre as migrações de retirantes sem trabalho durante a seca combinava-se com a necessidade estratégica de estimular as migrações de trabalhadores para a área dos seringais amazônicos.

Contudo, apesar desses maciços investimentos, e mesmo em função deles, as estratégias de controle da população retirante invariavelmente refletiam os conflitos que, por sua vez, não cessavam de acontecer. O interventor federal, em telegrama a Vargas, reconhecia que em "vários lugares tem havido tentativas de assaltos, depredação de casas comerciais, obrigando fechamento de estabelecimentos, negocios, repartições arrecadadoras, inclusive da União"22.

Em Senador Pompeu, por exemplo, o comércio permanecia fechado. Uma comissão da Associação Comercial denunciou a presença ameaçadora de 2.000 flagelados na cidade, e "apela mais uma vez" aos "sentimentos humanitários" do governo para que este interferisse junto ao "chefe da Nação" no sentido de que fossem tomadas "medidas suficientes" que solucionassem a "vexatória situação" em que se encontrava o comércio local ${ }^{23}$. Ao mesmo tempo, as estações de trem continuavam sob a constante ameaça de assalto pelos retirantes. Em Luna, cerca de 50 pessoas invadiram o trem e viajaram em direção a Fortaleza nos vagões de carga. $\mathrm{Na}$ estação de Arrojado Lisboa, um número indefinido de famintos tomou de assalto o comboio da R.V.C. "com o propósito de viajar até a capital cearense". A regularidade do serviço ferroviário ficou comprometida, segundo a notícia, pelas "constantes ameaças de assaltos dos flagelados", que colocavam dormentes nas linhas e exigiam pela força a entrada nos vagões (O Povo, 5 e 9 de janeiro de 1943).

As ações da multidão somente foram interrompidas com as primeiras chuvas, atraindo os agricultores de volta à terra, que deveria ser rapidamente preparada para a próxima colheita. Ao mesmo tempo, as chuvas solaparam as bases de legitimidade que essas ações possuíam no interior da sociedade. Sem a seca a justificar o aumento da miséria e da fome, a pressão dos grupos de famintos tornou-se inaceitável e passível de repressão policial.

A chegada de um "inverno" regular em março de 1943 recolocou também a necessidade de encaminhar os retirantes de volta aos seus locais de moradia no interior do Estado. Com o auxílio da Legião Brasileira de Assistência e do governo estadual, o Dispensário dos Pobres empreendeu uma campanha de auxílio ao regresso dos retirantes ao interior, com a concessão de passagens de trem, sementes e uma quantia em dinheiro. O campo de concentração do Alagadiço, sem fun- 
ção, foi alugado pelo SEMTA para "a formação de um dos seus núcleos de famílias em Fortaleza" 24 .

No dia 15 de março de 1943 foi inaugurada a Hospedaria Getúlio Vargas que, segundo O Povo, "pode ser apontada, hoje, como um modelo de organização". A cerimônia de inauguração teve a presença do próprio ministro do Trabalho, sr. Marcondes Filho, além do interventor Menezes Pimentel, do general Gil Castelo Branco e de outras altas autoridades. O discurso oficial da cerimônia ficou a cargo do delegado regional do Trabalho, dr. Raul Domingues Uchôa, que "teceu um hino à fortaleza do cearense que vai, com energia e patriotismo, desbravar a Amazônia ciclópica". A nova hospedaria foi programada com uma "capacidade para manter, com relativo conforto, um total de 1.200 pessoas", em que cada família "participa diariamente de três refeições e aguarda, confiante, o dia do embarque para o extremo norte". A presença de altos dignitários do Estado Novo indicava a importância dada a esta nova instituição, encravada na encruzilhada de dois planos estratégicos do governo brasileiro naquele momento: controlar a mobilidade da população retirante durante as secas e participar efetivamente do esforço de guerra aliado à produção da borracha amazônica.

Apesar de pretender ser uma instituição permanente, a Hospedaria "tinha por finalidade oferecer pouso provisório, na travessia daqui para o Norte, aos flagelados nordestinos que iam compor o exército da borracha - não por coincidência também o exército da reserva" ${ }^{25}$.

Porém, a despeito dos discursos inflamados e dos investimentos políticos realizados na construção do imenso casarão "da rua Olavo Bilac", este iria se tornar o centro dos maiores conflitos entre retirantes e autoridades de Fortaleza durante as secas na década de 1950, quando, em vez do projetado, recebeu até 11 mil pessoas, que lotaram não só suas dependências internas, mas todas as áreas livres ao redor, em condições extremamente precárias de alojamento.

\section{O PADRÃO "ESTADO NOVO"}

As análises empreendidas até aqui indicaram algumas peculiaridades no relacionamento entre retirantes das secas e autoridades, que é preciso destacar mais conclusivamente.

As estruturas de sentimentos que se constituíram ao longo dos anos de 1877 a 1932 apontavam para uma combinação nas formas de percepção da pobreza, da mendicância e, especialmente, dos mecanismos de assistência aos pobres em momentos de crise. Ao mesmo tempo, os modelos liberal e paternalista - entendidos como formas ideais de concepção e organização do social - eram colocados em prática por autoridades e reclamados pelos retirantes, dependendo da situação histórica que se apresentava. 
Porém, a princípio, era o modelo liberal que se pensava estar mais de acordo com os padrões de desenvolvimento que se pretendia para o Brasil. Em vista disso, a hesitação em intervir diretamente no mercado de trabalho e de alimentos poderia nos levar a uma dupla e complementar interpretação.

Indicava, por um lado, uma esperança de que o equilíbrio entre oferta e demanda retornasse aos padrões "normais" sem que fosse necessária essa intervenção ou, antes, que essa intervenção poderia ser mais um fator a piorar a crise. Os relatórios das autoridades responsáveis pela aplicação de possíveis medidas corretivas - ministros, interventores e técnicos do IFOCS/DNOCS - eram claros em condenar as práticas anteriores de concentrar ou "abarracar" os retirantes, criar frentes de trabalho que não fossem adequadas às capacidades técnicas dos órgãos encarregados pelas obras ou, mais enfaticamente, a simples e "desmoralizante" distribuição de alimentos ou esmolas. Apesar do ambiente político favorável à intervenção, com as restrições aos mecanismos de participação política formal, tais autoridades procuraram, a princípio, deixar o mercado "livre" para buscar o equilíbrio que a crise decorrente da seca havia desfeito. Elas duvidavam, enfim, que quaisquer medidas de controle do mercado de trabalho e alimentos, a serem aplicadas no momento da seca, poderiam sanar o problema da escassez e da fome; pelo contrário, parece que temiam que fossem causar mais danos à população pobre e, principalmente, ao próprio mercado. Conscientemente ou não, incluíam-se no debate acerca do próprio liberalismo e sua fundamentação social e moral, além de sua eficácia prática para resolver situações de conflito; de fato, aludiam ao lugar a ser ocupado pelo mercado numa sociedade sujeita a crises periódicas que, se não são rigorosamente previsíveis, são parte da própria relação estabelecida entre a sociedade, tal como se estruturou no semiárido, e a natureza. A hesitação que manifestavam demonstrava que a crítica ao liberalismo efetuada pelos próceres do Estado Novo se resumia, prioritariamente, ao campo político; quanto ao mercado de alimentos, permanecia a crença em uma auto-regulação espontânea que tendia "naturalmente" a encontrar um equilíbrio entre seus componentes e que a intervenção só devia ser efetivada no caso de uma situação crítica.

A distinção entre liberalismo político e econômico servia para que se pudesse "negar o primeiro, mas apenas corrigir-se os exageros do segundo", de modo que o intervencionismo do Estado "não deveria chegar aos excessos totalitários de negação do mercado e do valor econômico de uma liberdade privada do indivíduo" ${ }^{26}$. A presença da multidão exigindo proteção, vinha forçar essas autoridades a intervir, já que colocava em questão a "segurança" social e ameaçava a ordem instituída. Assim, a regulamentação do mercado proposta implicitamente pelos retirantes, através de suas ações "espontâneas" e "tumultuárias", se contra- 
punha aos princípios do "livre mercado" defendidos pelo liberalismo econômico em suas várias versões. Se, para este, o mercado seguia leis que lhe eram inerentes e "naturais", para a multidão o mercado devia ser dirigido e regulamentado em tempos de crise para que não houvesse fome e sofrimento; enfim, às leis do mercado se contrapunha a "lei da vida", evidenciando uma visão rigidamente moralizada que se opunha a uma visão técnica e pretensamente objetiva. De fato, ao exigir distribuição de alimentos e abertura de frentes de trabalho, os retirantes forçavam um tipo de redistribuição da riqueza social que se baseava no pressuposto de que a escassez era socialmente localizada, ou seja, que apenas uma fração da população era afetada pela "seca", enquanto outra continuava fruindo dos benefícios da produção social.

Obviamente, só é possível distribuir alimentos se há alimentos em quantidade suficiente para ser distribuído. Este argumento prático, em sua efetividade, coloca em questão uma outra abordagem básica do pensamento liberal, que afirma que as crises são provocadas por um "declínio na disponibilidade de alimentos" que, todavia, não leva em consideração o relacionamento das pessoas com o consumo e a produção de alimentos, o que necessariamente envolve sistemas de poder, propriedade e direito ${ }^{27}$. A escassez, portanto, não seria um fato natural, mesmo se relacionada a um fenômeno climático, mas resultado de uma dada for124 ma de relações sociais que perpetua as desigualdades e baseia-se na produção de conflitos generalizados de interesses.

Este debate se reproduz nas interpretações formuladas sobre a seca. Ela pode ser vista - na perspectiva assumida pela grande maioria dos técnicos e autoridades governamentais - como um fenômeno da natureza que provoca uma escassez periódica, que deve ser combatido através do acúmulo de água em reservatórios cada vez maiores, priorizando "a captação de água e a melhoria e modernização tecnológicas com vistas ao aumento da produtividade". A questão social embutida na seca é tratada como uma incompatibilidade entre as possibilidades financeiras do Estado e as soluções técnicas já conhecidas para superar ou neutralizar a ausência ou irregularidade no abastecimento de água. O resultado é um discurso que se lamenta da falta de recursos e, no mesmo movimento, cobra incessantemente do governo federal uma política especial de financiamento para o "Nordeste", isto é, para a implementação de obras públicas de "combate às secas" ou para o incremento da economia "regional" que ampliaria aquelas possibilidades financeiras. Como se vê, esta perspectiva se inclui perfeitamente na abordagem liberal citada, assumindo integralmente a teoria do "declínio na disponibilidade de alimentos". Mas a seca pode ser entendida também a partir da idéia de que a "estrutura fundiária e econômica do Nordeste condena o pequeno produtor a cultivar apenas essas culturas de ciclo curto, sensíveis às variações do 
tempo e às chuvas irregulares", que "não se adaptam ao meio físico". As relações sociais, nesta outra perspectiva, tornam-se o ponto central na distribuição da riqueza social e se relacionam diretamente com a escassez que, de certa for$\mathrm{ma}$, beneficia aqueles que controlam as linhas de força sobre as quais estas relações são produzidas, através da ampliação dos latifúndios nos momentos de seca e da redução periódica do valor comercial das culturas produzidas pelos pequenos produtores num sistema de agricultura tradicional, onde se objetiva tão-somente obter uma precária "segurança alimentar"28.

As ações da multidão estão, portanto, conectadas, mas nem sempre articuladas com as disputas teóricas encetadas no âmbito - para elas inacessível - do mundo letrado onde se desenvolvem as políticas do Estado e as teorias econômicas.

Por outro lado, a hesitação das autoridades significava também o receio de enfrentar e entrar em confronto direto com comerciantes de alimentos e outros negociantes ou proprietários de terras que enriqueciam com o aumento de preços dos gêneros de primeira necessidade e com a queda nos preços dos lotes abandonadas pelos retirantes, mesmo em momentos como o período "pós-30" ou o Estado Novo. A agilidade administrativa demonstrada pelas autoridades em 1932 contrastava com a hesitação comumente evidenciada em outros momentos. Talvez isso se deva à presença do paraibano José Américo de Almeida à frente do Ministério da Viação e Obras Públicas num momento em que o governo provisório necessitava demonstrar um amplo controle da situação política, especialmente em função da guerra civil em São Paulo.

Mas, por outro lado, a relativa independência política do interventor Carneiro de Mendonça, ainda observada naquele ano, pode ajudar a explicar esta rapidez de movimentos: ele ainda podia ser visto como um "tenente" que pretendia se colocar acima dos conflitos entre grupos políticos rivais, imagem que se desfez no ano seguinte. Em 1942, ao contrário, a estreita vinculação do interventor Menezes Pimentel com grupos políticos e econômicos tradicionais impedia a mesma capacidade de intervenção técnica; esta ocorreu mais pela necessidade (externa) de braços para os seringais amazônicos, no contexto do esforço de guerra dos aliados. De qualquer maneira, em termos gerais, o trabalhismo demonstrou uma sensibilidade muito maior do que os governos "liberais" para com a chamada "questão social".

O controle estatal dos preços dos alimentos ou a sua distribuição aos retirantes eram atitudes adotadas em casos extremos, quando a iminência de uma revolta era sentida pelas autoridades, e a "segurança nacional" estava em jogo. O açambarcamento e a especulação de preços nas mercadorias fornecidas aos retirantes alistados em obras públicas, porém, eram amplamente conhecidos. As mu- 
danças nas formas de pagamento dos serviços demonstram esse conhecimento e a dificuldade em superá-lo positivamente: em 1932, quando "já se verificava a inflação nos preços dos gêneros ao dispor dos trabalhadores", ora "o abastecimento de víveres pela Cruz Vermelha" era abandonado "por implicar em maior dispêndio de recursos", ora "um sistema de fornecimento de víveres local sob a indicação e fiscalização do governo do Estado" era aplicado; mesmo assim, como os "atrasos no pagamento começaram a se intensificar", o interventor, "para não perturbar o andamento dos trabalhos e para que os comerciantes particulares não cortassem os suprimentos", resolveu distribuir os gêneros, “evitando dessa forma a paralisação dos trabalhos". A irregularidade e a frouxidão nas regras de abastecimento de víveres aos retirantes concentrados ou incorporados às obras públicas, além das dificuldades na fiscalização, favoreciam a corrupção e o aproveitamento por parte dos pequenos e grandes comerciantes, timidamente denunciados na imprensa - amarrada por compromissos políticos e econômicos e, mais do que isso, controlada de perto pelo DIP (Departamento de Imprensa e Propaganda) e pelo DEIP (Departamento Estadual de Imprensa e Propaganda).

Por parte dos retirantes, o momento das secas apenas agravava a desconfiança em relação aos comerciantes, transformando os locais de "fornecimento" em locais de permanente conflito. De qualquer maneira, a população retirante, aos cuidados do governo, formava um mercado tentador de dezenas, às vezes centenas de milhares de "consumidores" - na verdade, só um consumidor: o Estado - para os negociantes de gêneros alimentícios. Além de compensar uma discutível queda do consumo em função da crise, o "fornecimento" abria a oportunidade de manipular verbas públicas de emergência, "a fundo perdido", além de manipular os próprios retirantes em seu analfabetismo e em sua inabilidade na compreensão dos mecanismos escritos de comunicação.

Outra fonte de recursos ilícitos era a construção dos açudes e estradas, em que amplas possibilidades de super-faturamento ou irregularidades eram abertas pela falta de infra-estrutura de fiscalização, muito embora tais "deslizes" fossem menores do que os que ocorreriam em 1958. Além dos lucros monetários, uma conexão entre os políticos e os comerciantes garantia lucros políticos significativos para as lideranças locais, que negociavam vagas nos alistamentos e outros benefícios possíveis, como alistamento de várias pessoas da mesma família, ou de crianças, ou em vários "barracões" ao mesmo tempo ${ }^{29}$.

Assim, a convicção liberal na capacidade do mercado de retomar o equilíbrio em momentos de crise, não obstante as críticas oficiais do regime ao liberalismo político, permanecia influente entre as autoridades encarregadas de implementar as medidas de assistência aos retirantes. Ao tomá-las, os dirigentes estatais - estaduais ou federais - sabiam estar indo contra os princípios do mercado; fa- 
ziam-no, porém, na defesa da "segurança pública". Isso poderia explicar a recepção dos primeiros retirantes em Fortaleza, em 1932, pelas principais autoridades locais, especialmente policiais, além da vigilância permanente sobre os campos de concentração e de trabalho e sobre os passos dos retirantes pelas cidades.

Durante esse período (1930 a 1945), o padrão de relacionamento entre retirantes e autoridades, a despeito das críticas ao liberalismo político efetuadas pelo regime e da rapidez e profundidade das intervenções realizadas em 1932 e 1942, baseou-se ainda nos pressupostos do liberalismo econômico, da idéia de "mercado livre" e da crença nas "leis" do mercado, modelando uma forma de solucionar os conflitos decorrentes das invasões de retirantes, combinando elementos do paternalismo - a presença direta das autoridades nos locais "críticos", o controle do mercado de alimentos (em 1932) e a imediata distribuição de alimentos e vagas em obras públicas, que se assemelhavam à prática da "proteção" aos pobres em tempos de dificuldades - com a abordagem clássica do liberalismo, especialmente na esperança de retorno a um "ponto de equilíbrio" do mercado com a retirada das medidas intervencionistas.

O Estado Novo, afinal, não era tão novo assim...

\section{NOTAS}

${ }^{1}$ ALBUQUERQUE JR, Durval M. "Palavras que calcinam, palavras que dominam: a invenção da seca do Nordeste". In Revista Brasileira de História. São Paulo, ANPUH/Marco Zero, vol. 15, no 28, pp. 111-120; 1995, e NEVES, Frederico de C. A Multidão e a História: saques e outras ações de massas no Ceará. Rio de Janeiro: Relume Dumará, 2000.

${ }^{2}$ Em trabalho anterior, analisamos este programa e suas implicações do ponto de vista dos próprios retirantes. NEVES, Frederico de C. "Curral dos Bárbaros: os campos de concentração no Ceará (1915 e 1932)". In Revista Brasileira de História. São Paulo: ANPUH/Contexto, vol. 15, n 29, pp. $93-$ 122, 1995. Cf. também RIOS, Kênia S. "A cidade do Sol à sombra do flagelo". In Projeto História. São Paulo, EDUC, n 19 , novembro de 1999, pp. 215-225. Em 1915, já havia sido criado um campo de concentração em Fortaleza, quando uma elevada taxa de mortalidade causou um grande impacto entre a população da cidade. Cf. TEÓFILO, Rodolfo. A Seca de 1915. $2^{a}$ ed, Fortaleza: Ed. UFC, 1982; e QUEIROZ, Raquel de. O Quinze. 52a ed, São Paulo: Siciliano, 1993.

${ }^{3}$ SOUZA, Simone. “As Interventorias no Ceará (1930-1935)". In SOUZA, Simone de (Coord.) História do Ceará. Fortaleza: FDR, 1994, p. 321.

${ }^{4}$ GIRÃO, Raimundo. Pequena História do Ceará. 4 a ed, Fortaleza: Ed. UFC, 1984, p. 207.

${ }^{5}$ ALMEIDA, Ministro José Américo de. O Ministério da Viação no Governo Provisório. Rio de Janeiro: Officina dos Correios e Telegraphos, 1933, pp. 222-223.

${ }^{6}$ Correio da Semana, 5 de novembro de 1932. Esse artigo foi o primeiro de uma série de quatro reportagens sobre as condições do Campo de Concentração do Ipu.

${ }^{7}$ ESTADO DO CEARÁ. Relatório apresentado ao Exmo. Presidente da República pelo Interventor Federal Cap. Roberto Carneiro de Mendonça. 22 de setembro de 1931 a 5 de setembro de 1934. Fortaleza: Imprensa Official, 1936, p. 64. 
${ }^{8}$ Idem, p. 65. A “efficiencia dessa commissão" é demonstrada por um quadro que mostra a "quantidade de multas impostas ao comercio do Estado".

${ }^{9}$ GOMES, Ângela M. de Castro. A Invenção do Trabalhismo. Rio de Janeiro: Vértice, 1988, pp. 220-222.

${ }^{10}$ Cf. THOMPSON, E. P. “A economia moral da multidão inglesa no século XVIII”, e "Economia moral revisitada”. In Costumes em Comum. São Paulo: Companhia das Letras, 1998, pp. 150-202 e 203-266.

${ }^{11}$ DNOCS (Departamento Nacional de Obras Contra as Secas). Relatório dos Trabalhos Realizados no ano de 1942. São Paulo: DNOCS, 1942, p. 35.

${ }^{12}$ Padroeiro do Ceará, não por acaso São José simboliza a esperança de chuvas regulares no sertão. Por outro lado, a passagem do equinócio prenuncia, para os meteorologistas, a configuração do mapa pluviométrico que irá caracterizar a situação de "seca" ou de "inverno". Para os "profetas populares", ao contrário, pequenas alterações em elementos da natureza prenunciam a estação seguinte: as orelhas dos jumentos, o comportamento sexual das lacraias, etc.

${ }^{13}$ Arquivo Nacional, Telegramas Recebidos pela Secretaria da Presidência da República, 1942.

${ }^{14}$ HOBSBAWM, Eric J. Os Trabalhadores. Estudos sobre a História do Operariado. Rio de Janeiro: Paz e Terra, 1981, p. 15. Elaborado no contexto das rebeliões dos mineiros ingleses do início do século XIX, este conceito parece extremamente adequado às situações aqui analisadas.

${ }^{15}$ GUERRA, Paulo de Brito. Flashes das Secas. Fortaleza: DNOCS, 1983, pp. 22-23.

${ }^{16}$ Arquivo Nacional, Telegramas Recebidos pela Secretaria da Presidência da República, 1943.

${ }^{17}$ DNOCS (Departamento Nacional de Obras Contra as Secas). Relatório das Trabalhos Realizados no ano de 1942. op. cit., p. 27. O Superintendente observa ainda que "a afluência tumultuária de trabalhadores às obras cresce de valor como índice do desequilíbrio da vida na região quando se considera o fato iniludível de lutarmos, em regra, com dificuldade de braços para o andamento normal dos trabalhos da Inspetoria, o que tem condicionado a mecanização progressiva de nossos serviços" (p. 34). Isto é: em tempos "normais", há falta de mão-de-obra para as obras do DNOCS, o que é resolvido com a mecanização; no entanto, em tempos de seca, quando há excesso de mão-deobra, a mecanização impede a absorção de novos trabalhadores não qualificados.

${ }^{18}$ SOBRINHO, Tomás Pompeu. História das Sêcas (século XX). Fortaleza: Ed. Batista Fontenele, 1953, pp. 49-50.

${ }^{19}$ LENHARO, Alcir. A Sacralização da Política. $2^{a}$ ed, São Paulo: Papirus, 1986, pp. 56-57.

${ }^{20}$ VIEIRA, Ma do Socorro G. O "Soldado da Borracha". Discurso da Emigração numa Economia de Guerra. Monografia de Bacharelado em História apresentada à UFC. Fortaleza, 1993, pp. 7-8.

${ }^{21}$ O Povo, 1 de outubro de 1942. Somente em 29 de abril de 1943 a comissão declarou que a "missão está finda", ressaltando que a continuidade do trabalho de assistência só foi possível com a ajuda do governo do Estado, da LBA, do Comitê Britânico de Socorro às vítimas da guerra, do arcebispo de Fortaleza e do SEMTA. Gazeta de Notícias, 29 de abril de 1943.

${ }^{22}$ Arquivo Nacional, Telegramas Recebidos pela Secretaria da Presidência da República, 1943. Nunca é demais observar que as fontes que utilizamos, normalmente provenientes das classes dominantes, "exprimem mais um projeto ou um programa do que uma operação", e é nesta inflexão que devemos examiná-las. PERROT, Michelle. Os Excluídos da História. Operários, prisioneiros, mulheres. Rio de Janeiro: Paz e Terra, 1988, pp. 54-55. 
${ }^{23}$ O Povo, 5 de janeiro de 1943. A população do núcleo urbano de Senador Pompeu somente chegaria a ter 15.681 habitantes em 1950. A observar também que as demandas por ajuda passaram a ser encaminhadas diretamente ao governo federal e, assim, o governo estadual tornou-se um mero intermediário entre as necessidades locais e os órgãos federais, reforçando os laços estabelecidos diretamente entre Getúlio e o "povo”.

${ }^{24}$ O Povo, 5 de fevereiro de 1943; Gazeta de Notícias, 29 de abril de 1943. O prefeito de Boa Viagem, no entanto, reclamou da falta de sementes, pois as que chegaram não foram suficientes: "temos boas chuvas e falta absoluta de sementes". Arquivo Nacional, Telegramas Recebidos pela Secretaria da Presidência da República, 1943.

${ }^{25}$ ARAÚJO, Ma Neyára de O. A Miséria e os Dias: História Social da Mendicância no Ceará. São Paulo: Hucitec, 2000, p. 115.

${ }^{26}$ GOMES, Ângela de Castro. A Invenção do Trabalhismo. Op. cit., p. 223.

${ }^{27}$ THOMPSON, E. P. "Economia moral revisitada”. Op. cit., p. 229. A expressão “declínio na disponibilidade de alimentos" é representada pela sigla FAD ("food availability decline"). Avaliamos, em outra oportunidade, as possibilidades de utilização do conceito de "economia moral" fora de seu ambiente original - o século XVIII inglês. Cf. NEVES, Frederico de C. "Economia Moral versus Moral Econômica (ou: o que é economicamente correto para os pobres?)”. In Projeto História. São Paulo, EDUC, nº 16, fevereiro de 1998, pp. 39-58. Salim Rachid, em interessante artigo, levanta questão semelhante ao comparar os estudos de Adam Smith e alguns de seus seguidores com as políticas desenvolvidas pelos governos ingleses na Índia e na Irlanda no século XIX, que levaram a uma intensificação da fome e da miséria. Ele conclui que as "leis de mercado", de modo geral, se contrapõem à máxima romana - aceita por alguns políticos ingleses do século XVIII e, de certa forma, implícita em todas as relações entre sociedades desiguais e a pobreza - que assegura a primazia da subsistência popular sobre as leis econômicas: Salus populi Suprema Lex. RACHID, Salim. "The Policy of Laissez-faire During Scarcity”. In The Economic Journal, 90 (September 1980), pp. 493 e 498-499.

${ }^{28}$ CERQUEIRA, Paulo C. L. “A Seca no Contexto Social do Nordeste”. In CPT/CEPAC/IBASE. O Genocídio do Nordeste (1979-1983). São Paulo: Mandacaru, 1989, p. 36. Cf. também: SCHWARZ, Alf. "Lógica do desenvolvimento do Estado e lógica camponesa". In Tempo Social. São Paulo, vol. 2, no 1, 1990, pp. 75-114; e SCOTT, James C. The Moral Economy of the Peasant. London: Yale University Press, 1976. Para uma visão geral das secas: NEVES, Frederico de C. “A Seca na História do Ceará”. In SOUZA, Simone de (org.) Uma Nova História do Ceará. Fortaleza: Edições Demócrito Rocha, 2000, pp. 76-102.

${ }^{29}$ FROTA, Luciara S. de Aragão e. Documentação Oral e a Temática da Seca. Brasília: Centro Gráfico do Senado Federal, 1982, pp. 205 e 209.

Artigo recebido em 04/2000. Aprovado em 11/2000. 